\title{
Numerical Simulation of the 2004 Indian Ocean Tsunami: Case Study of Effect of Sand Dunes on the Spatial Distribution of Inundation in Hambantota, Sri Lanka
}

\author{
J.J. Wijetunge \\ Department of Civil Engineering, University of Peradeniya, Peradeniya 20400, Sri Lanka \\ Email: janakaw@pdn.ac.lk
}

(Received April 1, 2008; accepted August 2, 2009)

\begin{abstract}
The megathrust earthquake of moment magnitude $9.1-9.3$ on December 26, 2004 unleashed a massive tsunami which devastated the coastal belts of Sri Lanka as well as several other countries bordering the Indian Ocean. Extensive field observations carried out in Sri Lanka in the aftermath of the tsunami clearly showed that the spatial variation of the degree of destruction along the coastal belt was highly non-uniform. The coastal geomorphology, for instance, the presence of sand dunes in some parts of the coast, is one primary factor that had contributed to this nonuniformity. Accordingly, the present paper investigates, as a case study, the effect of a nearly $2 \mathrm{~km}$ long sand dune, lying along a part of the seafront of a city on the south coast of Sri Lanka, on the characteristics of the spatial distribution of inundation. Numerical simulations based on non-linear shallow water equations were carried out first with the sand dune and then without the dune to obtain the respective spatial distributions of the maximum values of the depth of inundation and the flow velocity as well as their temporal variations. The results appear to indicate that the peak flood flow rates and flow depths are higher in most areas of the city in the case without the dune compared to that with the dune. However, it appears that the tsunami surge backing up against the sand dune and other elevated beachfronts causes a rise in water level of up to $0.5 \mathrm{~m}$ in the case with the sand dune compared to that without the dune. Flow velocities in the absence of the dune too appear to be higher in most areas although there are patches of lower velocities at certain low elevation localities with elevated ground on either side.
\end{abstract}

Keywords: Shallow water equations, flow depth, flow velocity, tsunami arrival time, hazard mapping

\section{NOMENCLATURE}

$\begin{array}{ll}f & \text { Coriolis force coefficient } \\ g & \text { acceleration due to gravity } \\ h & \text { still water depth } \\ H & \text { total water depth } \\ n & \begin{array}{l}\text { Manning's relative roughness coefficient } \\ P\end{array} \\ & \begin{array}{l}\text { volume flux }(=h u) \text { in longitudinal (or } x \text {-) } \\ \text { direction }\end{array} \\ Q & \begin{array}{l}\text { volume flux }(=h v) \text { in latitudinal (or } y \text {-) } \\ \text { direction }\end{array} \\ R & \begin{array}{l}\text { radius of the Earth } \\ \text { depth-averaged velocity in longitudinal (or }\end{array} \\ & x \text {-) direction }\end{array}$

\section{INTRODUCTION}

The tsunami triggered by the megathrust earthquake of moment magnitude $9.1-9.3$ (Stein and Okal 2005) on December 26, 2004 in the Andaman-Sunda subduction zone caused enormous loss of life and damage to property in Sri Lanka and in several other countries

$\begin{array}{ll}v & \text { depth-averaged velocity in latitudinal (or } y \text {-) } \\ x & \text { direction } \\ y & \text { direction pointing to the east } \\ \zeta & \text { direction pointing to the north } \\ \rho & \text { density of sea water } \\ \tau_{x} & \text { bottom shear stress in } x \text {-direction } \\ \tau_{y} & \text { bottom shear stress in } y \text {-direction } \\ \Phi & \text { latitude of the Earth } \\ \psi & \text { longitude of the Earth }\end{array}$

bordering the Indian Ocean. In Sri Lanka, 13 of the 14 districts with a coastal boundary were affected: the death toll was over 35,000 with 20,000 injured and about 100,000 housing units either completely or partially damaged leaving half a million people homeless and causing massive disruption to livelihoods (Department of Census and Statistics, Sri Lanka 2005). 
However, the degree of the devastation along the coastal belt of Sri Lanka was not uniform: some areas suffered more damage, some less, and in certain other areas, often not far away, there was no damage at all. An analysis of the extensive field records of the extent of inundation in the affected coastal areas of the country clearly indicates that the coastal geomorphology is one primary factor that has contributed to the non-uniform pattern in the degree of destruction caused by the tsunami in December 2004 (Wijetunge 2006, 2009). One example is that sand dunes in certain parts of the south coast of Sri Lanka have prevented the tsunami from directly attacking the settlements in their shadow. These sand dunes of height up to around $10 \mathrm{~m}-12 \mathrm{~m}$ and with thick vegetation cover on top run parallel to and within $50-300 \mathrm{~m}$ of the shoreline (see, for example, Fig. 1). However, wherever gaps existed in the dune system, or at locations where the dune height was low or had been breached for various purposes, it appeared that the tsunami surge had rushed through with greater momentum causing considerable destruction.

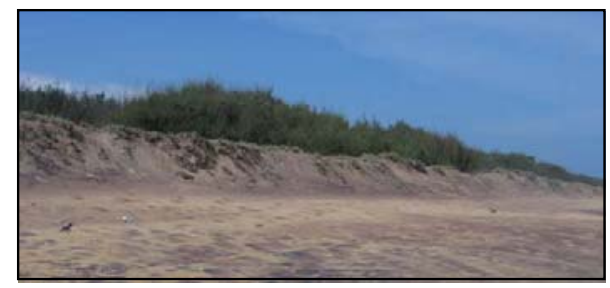

Fig.1. Sand dunes in Hambantota, Sri Lanka.

A typical case of a stretch of sand dunes affecting the pattern of tsunami flooding is the city of Hambantota on the south coast of Sri Lanka (see location map shown in Fig. 2): nearly $2 \mathrm{~km}$ long stretch of the coast protected by a large-scale sand dune, the central area of the city as well as the three salterns are marked on the satellite image of the city and surrounding areas shown in Fig. 3. The impact of the tsunami in the west part of the city without dunes or with only small-scale dunes was significantly more than the east part with large-scale dunes. It must, however, be added that the higher population as well as building densities in the west part of the city compared to those in the east also contributed to the larger number of casualties in the west part of the city.

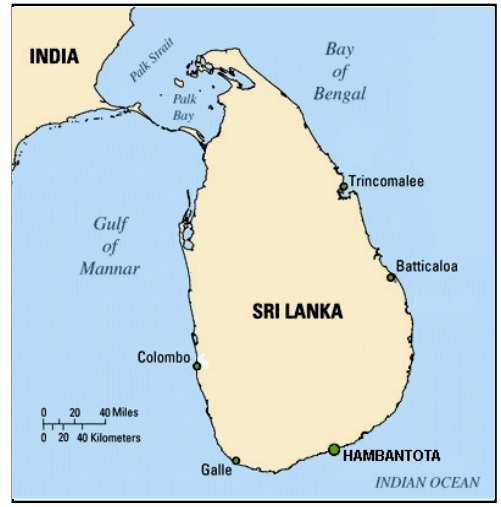

Fig. 2. Location map: city of Hambantota.

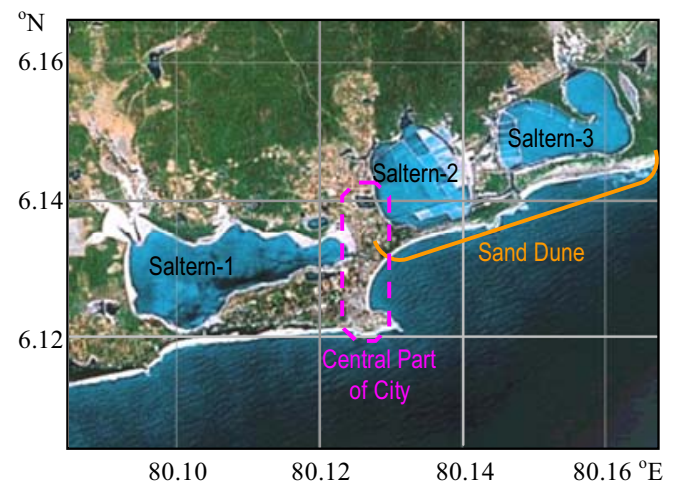

Fig. 3. A satellite image of the city of Hambantota and adjoining areas. (Source: Google Earth)

The apparent protection provided by such natural barriers against the 2004 tsunami has prompted some coastal planners to consider the possibility of employing man-made dikes to protect tsunami threatened cities of high commercial output. Such dikes have been in use in Japan to protect onshore lands against tsunami and storm surges. However, one important concern here is the effect that the presence of a sand dune or a dike may have on the unprotected areas on either side, viz., whether the presence of a dune or a dike will make the adjacent coastline on either side more vulnerable in the event of a tsunami or storm surge.

In the literature, we find a few previous works on the natural or man-made structures subjected to tsunami induced flow. A linear solution for the interaction of tsunami with coastal defence structures is given in Silva (2000). Their results show that dissipation effects are more important in the case of permeable coastal barriers. Tanaka (2006) numerically examined the effect of coastal vegetation structures as barriers to tsunami flood flow. The numerical simulations of Tomita and Honda (2007) suggest that macroroughness has a significant influence on the tsunami inundation process. Fernando et al. (2007) experimentally investigated the effects of coral reefs on coastal wave propagation and found substantial reduction in flow velocity owing to increase in the bottom drag. They also found that the exit flow velocity from a gap in the simulated coral cover is significantly higher compared to the surroundings. The effect of sharp topographic changes and macro-scale roughness structures in a built environment on the tsunami inundation was studied experimentally by Cox et al. (2008). However, none of the above studies provide sufficient insight into the present problem.

Accordingly, the present paper investigates, as a case study, the effect of the large-scale sand dune on the eastern side of the city of Hambantota on its west part, especially the central areas of the city fronted by either small-scale dunes of height less than about $3 \mathrm{~m}-4 \mathrm{~m}$ or no dunes at all, against the 2004 Indian Ocean tsunami.

The methodology adopted in the present study is that we carry out high-resolution numerical simulations of the inundation caused by the 2004 tsunami in the city of Hambantota with and without the sand dune. The field 
measurements of the points of maximum penetration of inundation in the city of Hambantota (Wijetunge 2006) are used to calibrate and verify the model simulations of flooding with the dune. We then employ the calibrated model to obtain the spatial distribution of inundation without the sand dune. The model results from both cases have been processed to obtain the maximum depth of inundation and the flow velocities as well as the differences between these parameters in the two cases.

\section{Numerical Modelling}

In the following, we outline the fault plane model and the hydrodynamic model employed to simulate the generation and the propagation of the 2004 tsunami. The nested grid set-up used in the hydrodynamic model is also described.

\subsection{Fault Plane Model}

Seismic inversion models (e.g., Lay et al. 2005) suggest that the rupture propagated approximately northward from the epicenter, located at $\left(95.51^{0} \mathrm{E}, 3.25^{\circ} \mathrm{N}\right)$, along $1,200 \mathrm{~km}-1,300 \mathrm{~km}$ of the Andaman-Sunda fault line for about $8-10$ minutes causing up to $6 \mathrm{~m}$ of bottom subsidence and $10 \mathrm{~m}$ of uplift over a region $100 \mathrm{~km}-$ $150 \mathrm{~km}$ wide across the subduction area.

The fault plane model adopted in the present study is that proposed by Grilli et al. (2007) who employed available seismic data as well as hydrodynamic data pertaining to the generation and propagation of the 2004 tsunami to iteratively develop a 5 -segment coseismic tsunami source for the December 26, 2004 event; see Fig. 4 and Table 1, respectively, for locations and source parameters of the 5 dislocation segments.

Table 1 Source parameters used in fault plane model of Grilli et al. (2007)

\begin{tabular}{|l|c|c|c|c|c|}
\hline $\begin{array}{l}\text { Segment/ } \\
\text { Parameter }\end{array}$ & S1 & S2 & S3 & S4 & S5 \\
\hline Length (km) & 220 & 150 & 390 & 150 & 350 \\
\hline Width (km) & 130 & 130 & 120 & 95 & 95 \\
\hline Dip (deg.) & 12 & 12 & 12 & 12 & 12 \\
\hline Rake (deg.) & 90 & 90 & 90 & 90 & 90 \\
\hline Strike (deg.) & 323 & 348 & 338 & 356 & 10 \\
\hline Depth (km) & 25 & 25 & 25 & 25 & 25 \\
\hline Slip (m) & 18 & 23 & 12 & 12 & 12 \\
\hline
\end{tabular}

The contours of initial surface elevation for the above co-seismic tsunami source, computed using Okada's (1985) dislocation model and reported in Grilli et al. (2007), is shown in Fig. 5. Further, it is assumed here that the sea surface follows the sea bed deformation instantaneously. Note that, in Fig. 5, the continuous lines represent uplift and dashed lines represent subsidence, both at $1 \mathrm{~m}$ contour intervals in the range $-5 \mathrm{~m}$ to $+8 \mathrm{~m}$. The background bathymetry is also plotted in grey at $500 \mathrm{~m}$ contour intervals.

In a subsequent study (Ioualalen et al. 2007), the numerical simulations based on this fault plane model showed good agreement with the measured run-up

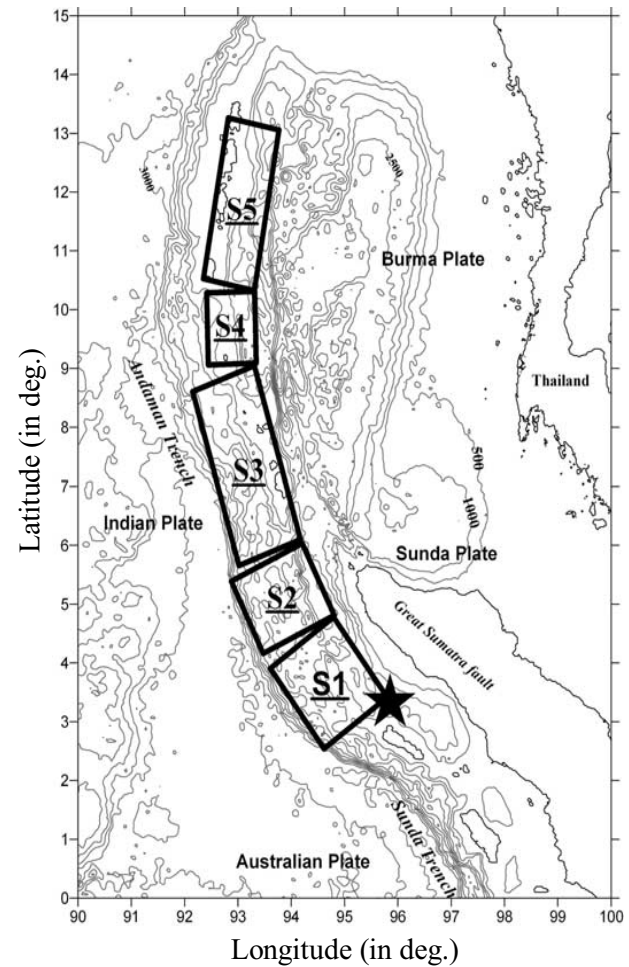

Fig. 4. Five segment source model adopted in the present study (see Table 1 for source parameters).

Contours show bathymetry around the December 2004 earthquake location (star) at $500 \mathrm{~m}$ intervals (after Ioualalen et al. 2007).

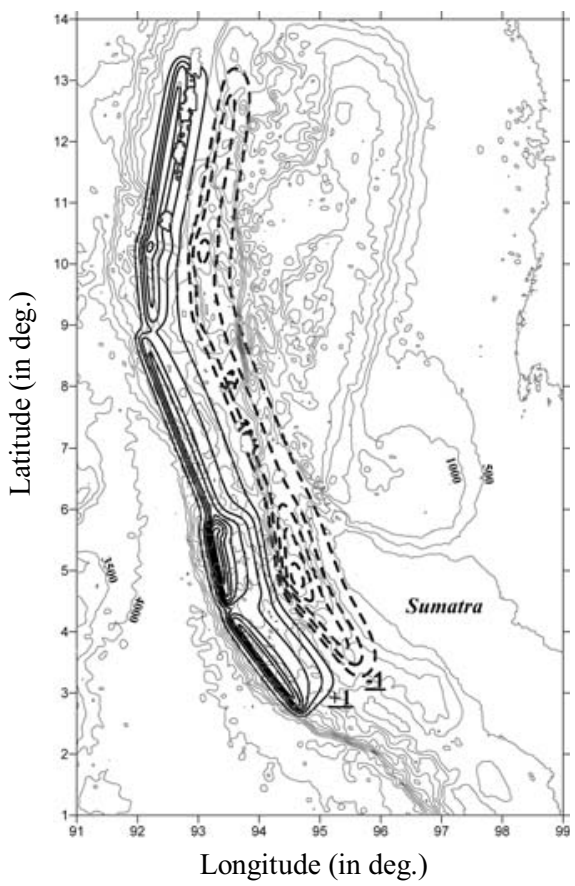

Fig. 5. Initial surface elevation for tsunami source. Continuous lines represent uplift and dashed lines represent subsidence, both at $1 \mathrm{~m}$ contour intervals in the range $-5 \mathrm{~m}$ To $+8 \mathrm{~m}$ (after Grilli et al. 2007). 
heights along the Andaman coast of Thailand. It must be added that Ioualalen et al.'s study is limited to computation of tsunami run-up heights, and does not present distribution of inundation onshore.

\subsection{Grid Set-Up for Hydrodynamic Model}

A dynamically coupled system of nested grids was employed to simulate the tsunami propagation from Andaman-Sunda subduction zone towards Sri Lanka and the subsequent inundation of the onshore areas of the cities under study. The bathymetric data for the largest grid employed in the simulations, i.e., Region 1 shown in Fig. 6, was obtained by interpolating ETOPO2 data with a resolution of 2 arc minutes to a grid of $0.6765 \mathrm{arc}$ minutes $(\sim 1250 \mathrm{~m})$ spacing. Region 2 , which is embedded in Region 1, is also shown in Fig. 6.

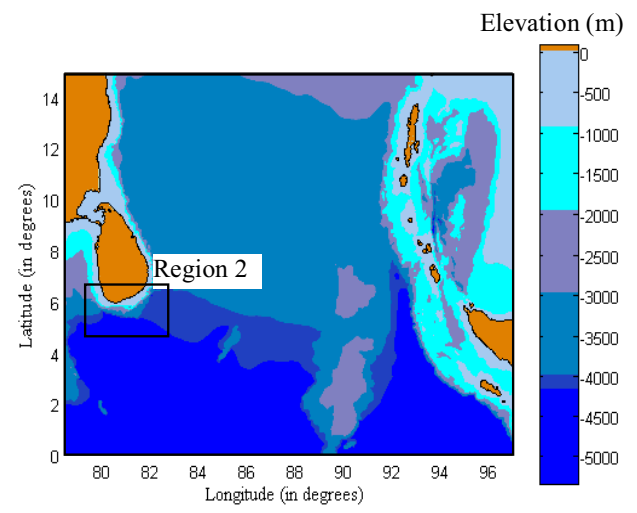

Fig. 6. Region 1 of the computational domain; location of Region 2 is also shown.

Elevation (m)

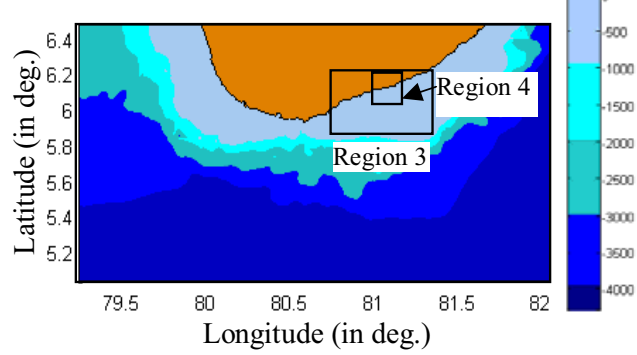

Fig. 7. Region 2 of the computational domain; locations of Regions 3 and 4 are also shown.

The bathymetric data for both Region 2 with a grid resolution of 0.1353 arc minutes $(\sim 250 \mathrm{~m})$ shown in Fig. 7 and for Region 3 (grid spacing $50 \mathrm{~m}$ ) were at first interpolated from ETOPO2 data before updating with data from the available navigation charts. These navigation charts typically covered depths down to about $3000 \mathrm{~m}-4000 \mathrm{~m}$ at scales of $1: 150,000$ or $1: 300,000$. The nearshore bathymetry of some areas was further updated with higher resolution navigation charts at scales of 1:10,000 and 1:15,000.

A fourth level grid with a grid spacing of $10 \mathrm{~m}$ was used to cover the city of Hambantota (see Fig. 8 for bathymetry and topography, and Fig. 7 for location of this grid with respect to Region 3). The topographic data for this grid was obtained from high resolution LIDAR (Light Detection and Ranging) survey data (The precise digital earth model of the coastal areas of Sri Lanka, Project Director: Prof. Fabrizio Ferrucci, Italy) made available to the author by the Disaster Management Centre of Sri Lanka. These LIDAR data have been acquired at a horizontal resolution of $1 \mathrm{~m}$ and a vertical resolution of not more than $0.3 \mathrm{~m}$ and were originally projected on to the UTM WGS84 - Zone 44N coordinate system. However, all results presented in this paper have been converted to Geographic (latitude/longitude) coordinate system in arc degrees with WGS84 as the datum using Global Mapper software.

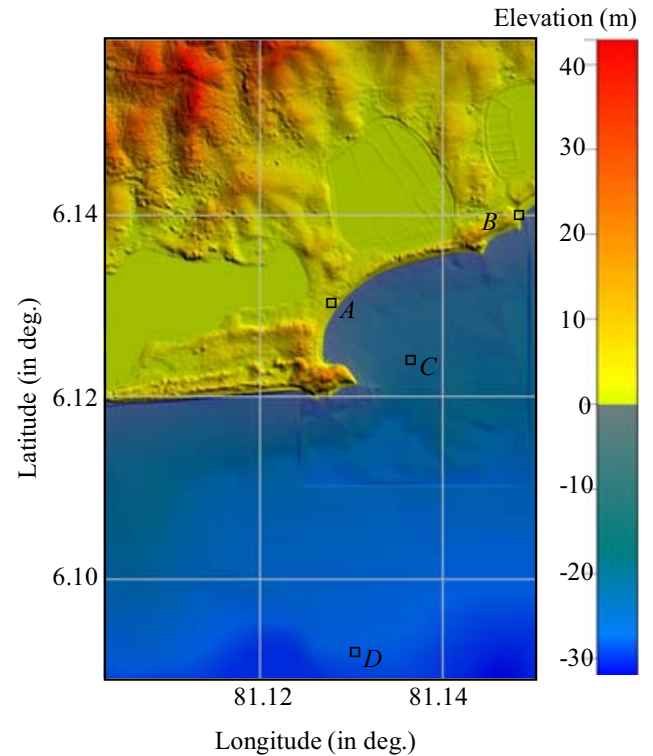

Fig. 8. Computational domain of Region 4 covering the city of Hambantota. The bathymetric and topographic elevations shown are with respect to Mean Sea Level.

\subsection{Hydrodynamic Model Formulation}

The mathematical model used in the present work is the Cornell Multi-grid Coupled Tsunami Model (COMCOT) which solves the non-linear shallow water equations on a dynamically coupled system of nested grids. An explicit leap-frog scheme together with centered finite differences is employed in the numerical discretization (further details can be found in Liu et al. 1998). The model has been validated by experimental data (Liu et al. 1995) and has been successfully used to investigate several historical tsunami events, such as the 1960 Chilean tsunami, the 1992 Flores Islands (Indonesia) tsunami (Liu et al. 1994, 1995), and more recently, the 2004 Indian Ocean tsunami (Wang and Liu 2006, 2007).

Using a nested grid system, COMCOT is capable of simultaneously calculating the tsunami propagation in ocean as well as the inundation in the targeted coastal areas. In the nested grid system, the inner (finer grid) regions adopt a smaller grid size and time step and are nested inside an outer (larger grid) region. At the beginning of each time step, along the interface of two 
different regions, the volume flux, which is product of water depth and depth-averaged velocity, is interpolated from the outer (larger grids) region into inner (finer grids) region. The water surface elevations and the volume fluxes in the inner (finer grids) region are calculated and the resulting free surface elevations are averaged to update those values in the larger grids, which overlaps the inner region. The volume fluxes in the outer (larger grids) region can also be updated. With this algorithm, we can capture nearshore features of tsunami dynamics with a high spatial and temporal resolution, and at the same time, we can still maintain a high computational efficiency.

To simulate onshore flooding, a moving boundary scheme described by Cho (1995) was employed, in which the "shoreline" is defined as the interface between a wet grid and its adjacent dry grids. Along the "shoreline", the volume flux is assigned to be zero. Once the water surface elevation at the wet grid is higher than the land elevation in its adjacent dry grids, the "shoreline" is moved one grid toward the dry grid and the volume flux is no longer zero and needs to be calculated by the governing equations (Wang and Liu 2007).

The amplitude of the 2004 Indian Ocean tsunami during its propagation in the ocean basin and continental shelf was in the order of magnitude of $1 \sim 2 \mathrm{~m}$, whilst the typical water depth is around 3 to $4 \mathrm{~km}$ in ocean basin and is in the order of magnitude of $100 \mathrm{~m}$ on the shelf. Therefore, the nonlinearity is relatively small and can be ignored. In addition, the wavelength of the leading wave was in the order of magnitude of $100 \mathrm{~km}$ in ocean basin and $10 \mathrm{~km}$ nearshore, about two orders of magnitude larger than water depth, indicating that the dispersive effect is not of importance (Wang and Liu 2007). Thus, linear shallow water equations are adequate to solve tsunami propagation in Regions 1,2 and 3 .

On the other hand, in the inundation areas in Region 4, the water depth becomes very small and approaches zero at the tip of the surging bore. Thus, the nonlinearity, i.e., the wave amplitude to depth ratio, could become significant. However, owing to the shallowness of the water, the frequency dispersion effects, which are represented by the water depth to wave length ratio, can still be negligible (Wang and Liu 2007). Moreoevr, Horrillo (2006) who carried out model simulations of the 2004 tsunami with and without the inclusion of dispersive effects by employing Boussinesq and shallow water equations, respectively, found that the non-linear shallow water equations reproduce general features of the propagation with accuracy sufficient for most practical purposes. Considering these, we adopt non-linear shallow water equations inclusive of bottom frictional terms to describe the tsunami overland flow in Region 4.

As the spatial extent is comparatively larger in Regions 1 and 2, we use the linear shallow water equations on the spherical coordinate system as given in the following:

$$
\begin{aligned}
& \frac{\partial \zeta}{\partial t}+\frac{1}{R \cos \varphi}\left[\frac{\partial P}{\partial \psi}+\frac{\partial}{\partial \varphi}(\cos \varphi Q)\right]=0 \\
& \frac{\partial P}{\partial t}+\frac{g h}{R \cos \varphi} \frac{\partial \zeta}{\partial \psi}-f Q=0 \\
& \frac{\partial Q}{\partial t}+\frac{g h}{R} \frac{\partial \zeta}{\partial \varphi}+f P=0
\end{aligned}
$$

However, given the comparatively smaller spatial extents of Regions 3 and 4, we solve the governing equations in Cartesian coordinate system in these regions. The non-linear shallow-water equations in Cartesian coordinate system can be expressed as:

$$
\begin{aligned}
& \frac{\partial \zeta}{\partial t}+\frac{\partial P}{\partial x}+\frac{\partial Q}{\partial y}=0 \\
& \frac{\partial P}{\partial t}+\frac{\partial}{\partial x}\left(\frac{P^{2}}{H}\right)+\frac{\partial}{\partial y}\left(\frac{P Q}{H}\right)+g H \frac{\partial \zeta}{\partial x}+\tau_{x} H=0 \\
& \frac{\partial Q}{\partial t}+\frac{\partial}{\partial x}\left(\frac{P Q}{H}\right)+\frac{\partial}{\partial y}\left(\frac{Q^{2}}{H}\right)+g H \frac{\partial \zeta}{\partial y}+\tau_{y} H=0
\end{aligned}
$$

The bottom shear stress terms are modelled by using the Manning's formula as:

$$
\begin{aligned}
\tau_{x} & =\frac{\rho g n^{2}}{H^{7 / 3}} P\left(P^{2}+Q^{2}\right)^{1 / 2} \\
\tau_{y} & =\frac{\rho g n^{2}}{H^{7 / 3}} Q\left(P^{2}+Q^{2}\right)^{1 / 2}
\end{aligned}
$$

In Eq. (3), we utilize the Manning's relative roughness coefficient $(n)$ to parameterize the land surface condition. The presence of buildings and other structures, if sufficiently strong, too retard the tsunami flood flow and help dissipate energy, however, inclusion of such effects in two-dimensional depthaveraged model formulations remains a challenge. It may also be added here that Fujima (2001) attempts to quantify and incorporate bottom roughness whose size is large but smaller than the grid size in numerical model formulations based on shallow water equations.

Coriolis force effect is not considered for second, third and fourth level grids because of their smaller spatial extents. Furthermore, the time step for the model simulations was determined based on the Courant condition and varied from $2 \mathrm{~s}$ in Grid 1 to $0.25 \mathrm{~s}$ in Grid 4

\section{RESUltS AND DiscusSiON}

The model results from simulations with and without the sand dune were processed to obtain the corresponding spatial distributions of the maximum values of the depth of inundation and the flow velocity as well as their temporal variations. We also compute the differences in some of the above quantities between the two cases of with and without the sand dune. Moreover, tsunami arrival time contours were also computed based on the first $1 \mathrm{~cm}$ rise of the mean water level.

\subsection{Tsunami Arrival Times}

The computed arrival time contours for the 2004 tsunami are shown in Fig. 9 for the city of Hambantota. 
The results shown are from the simulation carried out with the sand dune in place.

We see in Fig. 9 that the tsunami wave fronts approach the city of Hambantota from a south to south-easterly direction whilst undergoing bathymetric depth refraction as well as other nearshore wave processes.

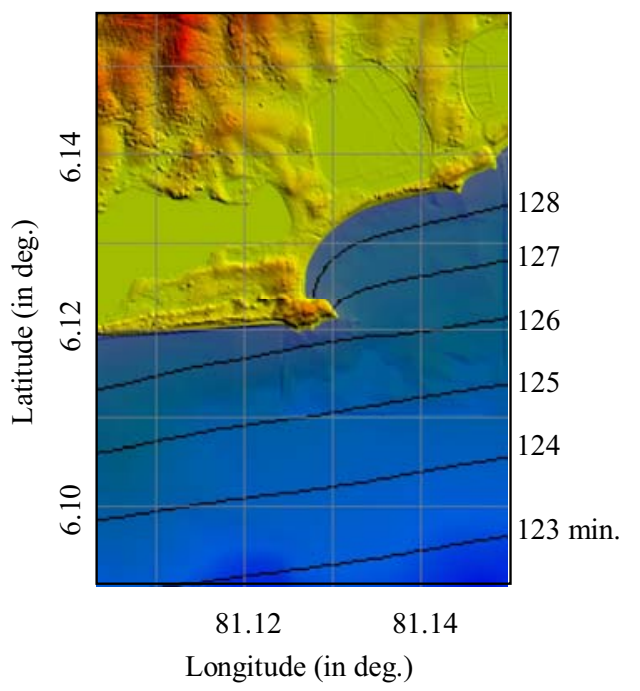

Fig. 9. Computed tsunami arrival time contours.

The numerical simulations suggest an arrival time of around 129 minutes whilst the Geological Survey and Mines Bureau of Sri Lanka (GSMB, unpublished) report tsunami reaching the main bus terminal, which is located about $100 \mathrm{~m}$ from the shore, 135 - 140 minutes after the earthquake. Moreover, Inoue et al. (2007) report that the clock that was on the clock tower located near the central bus station had stopped at 9:22 AM local time, i.e., 143 minutes after the earthquake, probably corresponding to the arrival of the maximum wave which according to some eyewitnesses was the first wave. However, another eyewitness account reported in Inoue et al. suggests an arrival time of 130 minutes for the first wave. Moreover, Papadopoulos et al. (2006) suggest, based on eyewitness accounts, that the second wave was the largest and that it arrived in Hambantota about $143-146$ minutes after the earthquake.

It must be noted that, although the earthquake started at 00:59 UTC off northern Sumatra, and propagated towards Andaman-Nicobar islands over a duration of about $8-10$ minutes, the numerical simulation assumes an instantaneous rupture at 00:59 UTC. However, it is likely that, considering the inclination of the longitudinal axis of the rupture zone, the primary forcing for the tsunami that arrived in the south coast of Sri Lanka may have been from Nicobar area of the fault plane where the rupture may have occurred about 5 - 7 minutes after that at the epicentre. Secondly, the computed arrival times correspond to the first $1 \mathrm{~cm}$ rise of water level, although the crest of the wave, which most people may have noted, would have arrived about 5 - 10 minutes later depending on the period of the wave. Thirdly, as mentioned by Inoue et al. (2007), some of the eyewitnesses may not have been wearing watches during the tsunami, so they depended only on their sense of time; furthermore, some eyewitnesses may not have seen the first wave because they were not near the ocean at that time, so the first wave of an eyewitness does not necessarily correspond to the actual first wave. These observations perhaps explain, at least partly, the apparent discrepancy of about 10 minutes between simulated and observed tsunami arrival times. It must also be added that the discrepancy of 10 minutes is only about $8 \%$ of the total propagation time of the 2004 tsunami from its source to the south coast of Sri Lanka.

\subsection{Onshore Inundation}

In the following, we utilize the model simulations with and without the sand dune to identify the influence of the presence of the dune on the characteristics of inundation in the city of Hambantota due to an event similar to the 2004 tsunami. First, let us consider in Fig. 10, the spatial distribution of the maximum depth of inundation: the results shown refer to the model simulations with the sand dune in place, and the arrows indicate the primary flow paths of onshore inundation. Following Walsh et al. (2003), the computed tsunami inundation is shown in three colour-coded depth ranges: $0-0.5 \mathrm{~m}, 0.5-2 \mathrm{~m}$, and greater than $2 \mathrm{~m}$. These depth ranges have been chosen because they are approximately knee-high or less, knee-high to headhigh, and more than head-high. The probable limit of tsunami inundation is the landward edge of the green zone.

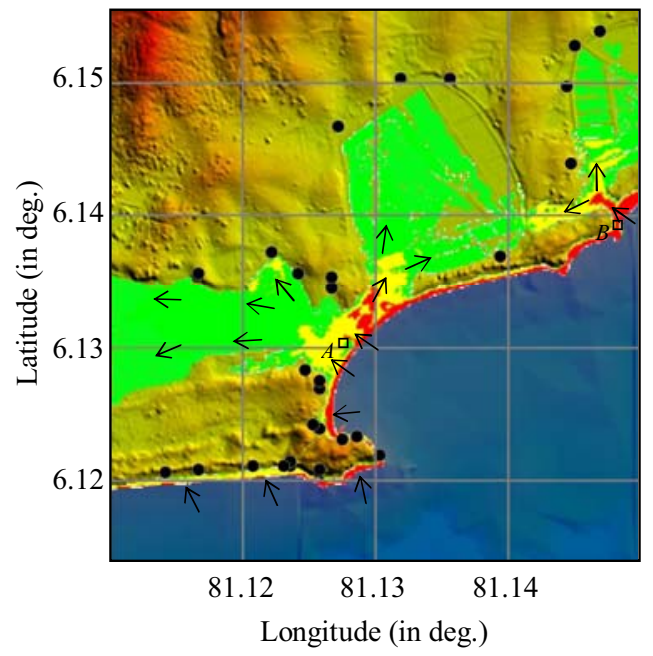

Fig. 10. Computed spatial distribution of inundation for the case with the sand dune. Elevation scale for topography and bathymetry as in Fig. 8 .

The solid circles are the points of furthest penetration of inundation from the extensive field measurements that were carried out by the author in the immediate aftermath of the tsunami (Wijetunge 2006). These field measurements were used to verify the model simulations that were carried out with a Manning's bottom roughness $(n)$ value of 0.02 , which is the typical value of $n$ for firm soil, for all onshore areas except 
over the salterns, where $n=0$ was used. We see that, the model simulated extent of inundation agrees well with the measured points of maximum penetration of inundation at most locations. It must be added that the points of furthest penetration of inundation from the field measurements do not necessarily correspond to locations where the depth of flooding had been zero; instead, it is likely that the field measurements indicate the locations where the water depth had been very low, probably up to around $30 \mathrm{~cm}-50 \mathrm{~cm}$. On the other hand, the model simulated furthest limit of inundation in the present results corresponds to a threshold water depth of $5 \mathrm{~cm}$. As mentioned in section 2.3, the formulation of bottom boundary shear employed in the present model is not expected to account for all means of energy dissipation for a tsunami wave surging onshore over an urban landscape. In the case of a breaking tsunami wave, the energy dissipation through breaking too is not simulated in shallow water numerical formulations. Furthermore, shallow water wave models may not produce a complete representation of the flow field over sudden changes in water depth, for instance over a dune, because such model formulations are based on the assumption of a uniform velocity profile across the flow depth. Nevertheless, despite these fundamental limitations, the present results appear to further confirm that the nonlinear shallow water wave models can predict the spatial distribution of inundation with accuracy sufficient for most practical purposes such as tsunami hazard mapping for evacuation planning, provided that accurate topographic and bathymetric data are used in the model simulations.

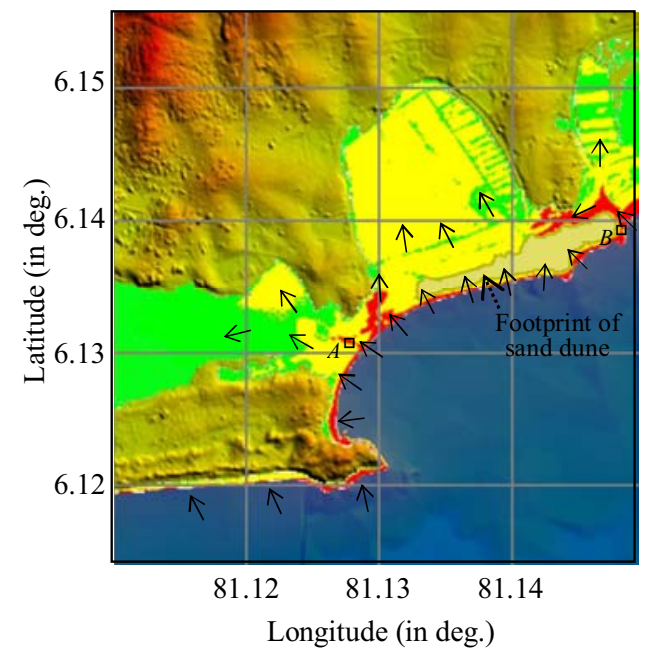

Fig. 11. Spatial distribution of inundation without the sand dune. The footprint of the sand dune is also overlaid on the simulated inundation. Elevation scale for topography and bathymetry as in Fig. 8 .

We now consider in Fig. 11 the spatial distribution of inundation obtained from the model simulations without the sand dune. The colour coding for the inundation depth is the same as that used in the earlier case with the dune. The footprint of the sand dune that was removed is also overlaid on the simulated inundation.
In order to further understand the time variation of the tsunami incursion, we also examine in Fig. 12 three snapshots each of the simulated inundation patterns at $t=136 \mathrm{~min} 40 \mathrm{sec}, 138 \mathrm{~min} 40 \mathrm{sec}$ and $143 \mathrm{~min} 20 \mathrm{sec}$, where $t$ is the time after the earthquake: frames $(a),(b)$, and $(c)$ with the sand dune; $(d),(e),(f)$ without the sand dune.

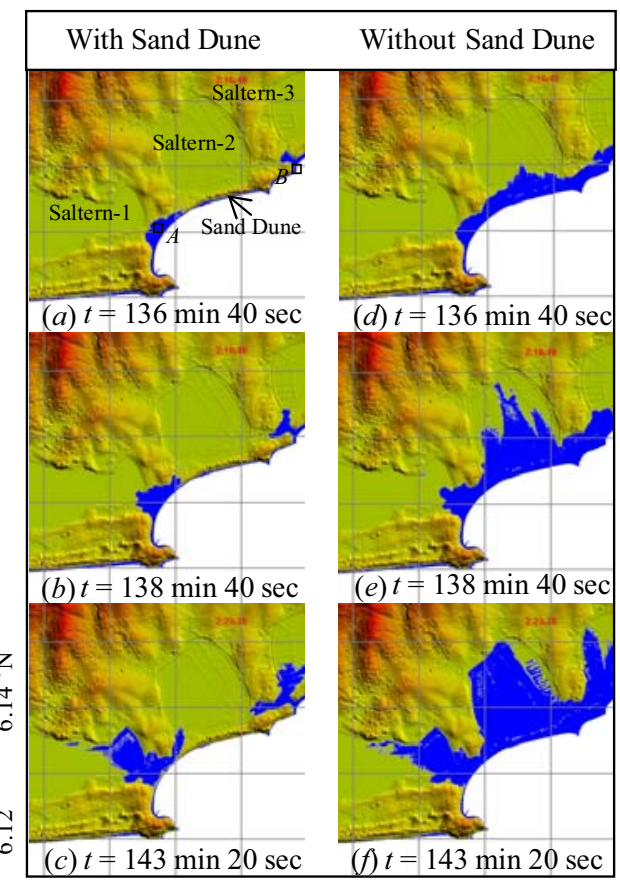

$81.12 \quad 81.14^{\circ} \mathrm{E}$

Fig. 12. Snapshots of spatial distribution of inundation at different elapsed times $(t)$ after the earthquake: $(a)$,

$(b),(c)$ with sand dune, and $(d),(e),(f)$ without sand dune. Areas in white depict the nearshore sea.

Elevation scale for topography as in Fig. 8.

The numerical simulations, both with and without the sand dune, indicate that the tsunami wave front first attacked the south coast of the city lying along latitude $\sim 6.12{ }^{\circ} \mathrm{N}$. However, there is no significant onshore incursion of flood water in this area owing to the presence of a stretch of sand dunes of height around 5 $\mathrm{m}-7 \mathrm{~m}$. We also see that the horizontal inundation distances are lower in that part of the coast lying between latitude $6.12{ }^{\circ} \mathrm{N}$ and $6.13{ }^{\circ} \mathrm{N}$ to the south of location $A$ due to the hilly nature of the onshore topography there with steep beach fronts. Fig. $12 a$ confirms that the tsunami waves cannot overtop the sand dune under consideration, so the area behind, i.e., saltern-2 and its surrounding, is protected from direct tsunami attack. However, flood water gets channelled towards saltern-2 across low elevation areas on either side of the dune, see Fig. $12 b$ and $c$. Moreover, as would be expected, saltern-2 gets inundated more rapidly as a result of direct tsunami attack in the second case, i.e., without the sand dune, see Fig. $12 d, e$ and $f$. It is also clear that the volume of flood flow rushing to salterns-2 and -3 and the adjoining areas is larger for the case without the sand dune. 
Meantime, the tsunami surge rushing through the neighborhood of locality $A$ travels towards saltern-1 probably picking up further momentum as the terrain there is sloping towards the saltern. Note that the area surrounding location $A$ is comparatively low lying with elevated terrain to the north and the south, and is also heavily populated with housing and other buildings including schools (see also Fig. 13 for footprints of housing and other buildings in the city), so the loss of lives and damage to property in this area during the 2004 tsunami was particularly high.

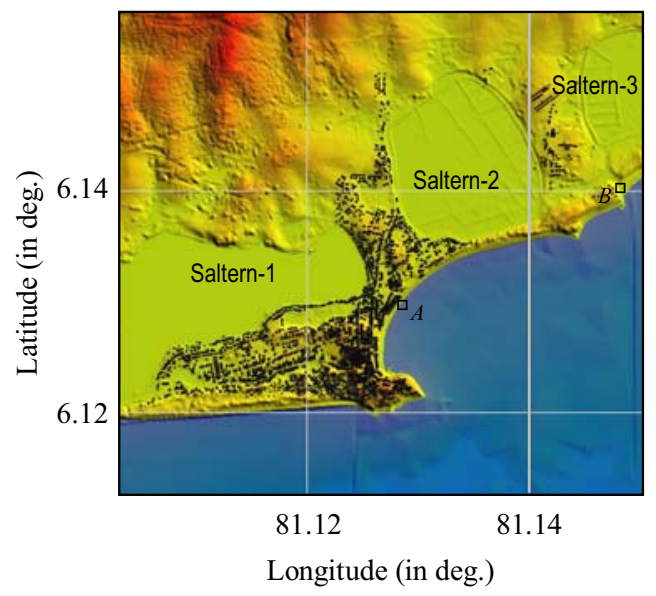

Fig. 13. Footprints of housing and other buildings overlaid on a topography map of the city of

Hambantota. Elevation scale for topography and bathymetry as in Fig. 8.

It is also interesting to examine the difference in maximum depth of inundation between the two cases, i.e., with and without the sand dune, see Fig. 14. The values shown in Fig. 14 have been obtained by subtracting the maximum depth of inundation at each grid point for the simulation with the sand dune from that without the sand dune, so positive values indicate higher flow depths in the case without the dune.

We see in Fig. 14 that peak flow depths in most areas would be higher without the dune compared to that with the dune. The model results indicate that the flow depths in saltern-2 are higher by up to about $1.5 \mathrm{~m}$ without the dune compared to with the dune. This is not entirely surprising as a larger volume of water falls straight into low-lying saltern-2 in the absence of the dune. We also see that, in the area to the west of location $A$, the maximum flow depths without the sand dune are larger by not more than $0.5 \mathrm{~m}$. So, it appears that the presence of the sand dune has reduced the flow depths in most areas of the city of Hambantota.

However, there is a narrow band of higher water elevations adjacent to the shoreline for the case with the dune compared to that without the dune (negative flow depths in shades of green). The water level data from both cases indicate that this rise in water level adjacent to the shoreline, most likely caused as a result of tsunami surge backing up against the high elevated beach fronts including the dune, varies from about 0.1 m in the vicinity of locations $A$ and $B$, where the dune elevation is low, and about $0.2 \mathrm{~m}$ in front of steep beach fronts south of location $A$ to $0.3 \mathrm{~m}-0.5 \mathrm{~m}$ in front of the large sand dune.

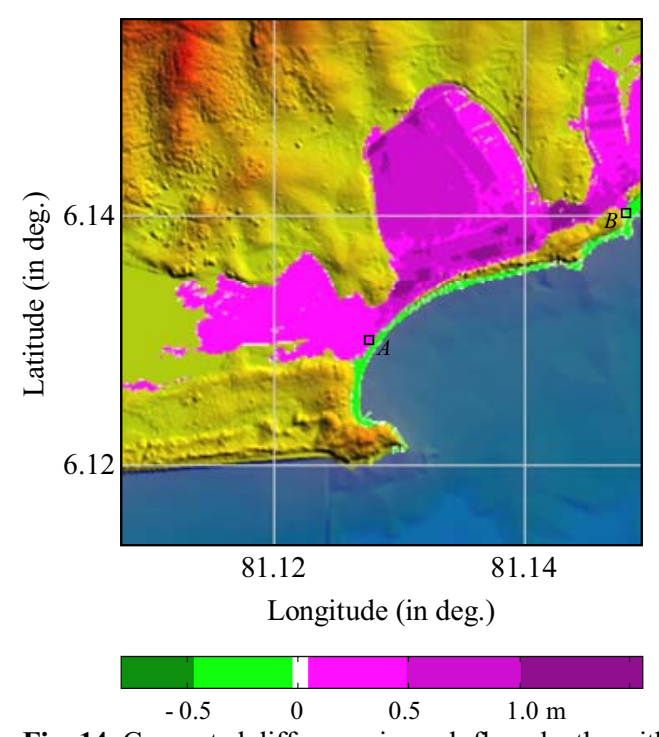

Fig. 14. Computed difference in peak flow depths with and without the sand dune. Negative values in the colour scale indicate higher flow depths in the case with the sand dune. Elevation scale for topography and bathymetry as in Fig. 8 .

In order to verify that the approaching tsunami wave profiles at locations sufficiently offshore are identical in both cases, we examine in Fig. $15 a$ the water level variation at location $D$ (marked on Fig. 8), where the water depth is $30 \mathrm{~m}$. Note that only the positive part of the leading wave is shown to ensure clarity of the comparison. Fig. $15 a$ confirms that the incident tsunami forcing is the same in both cases sufficiently away from the coast, in this instance at a water depth of $30 \mathrm{~m}$. We also plot in Fig. 15b, the water level variation at a location closer to the shore, i.e., location $C$ (see Fig. 8), where the water depth is $10 \mathrm{~m}$. Fig. $15 b$ indicates that the peak elevation of the leading wave closer to the shoreline is slightly higher, by about $0.1 \mathrm{~m}$, for the case with the dune compared to that without the dune. Figure 15 also indicates that the amplitude of the leading wave increases by as much as $50 \%$ as it travels from $30 \mathrm{~m}$ to $10 \mathrm{~m}$ deep water owing to nearshore wave transformations such as shoaling and probably due to the effect of the bay according to Green's law as well.

In the case of with the sand dune, a part of the tsunami surge rushing through the locality of $A$ veers towards saltern-2 as well. However, in the second case without the dune, the higher water surface elevations in saltern2, owing to direct flow across that part of the coastline where the dune was, appears to be blocking any significant flow of water from around locality $A$ towards saltren-2, and consequently, flow depths in the vicinity of location $A$ appear to be higher without the dune compared to the same with the dune. 


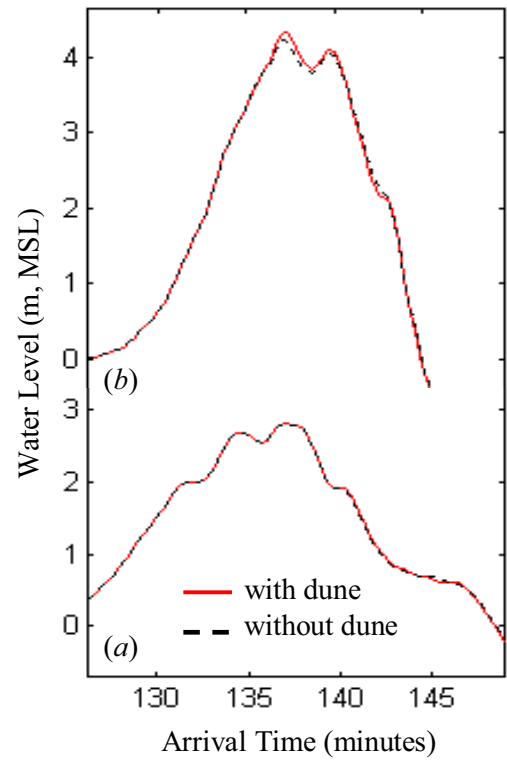

Fig. 15. Comparison of water levels with and without the sand dune at: $(a)$ location $D$ (water depth $=30 \mathrm{~m}$ ), and $(b)$ location $C$ (water depth $=10 \mathrm{~m})$ shown in Fig. 8.

Another important parameter that describes the intensity of tsunami overland flow is the flood velocity. So, we consider in Fig. 16 the maximum differences in the magnitude of the flow velocities between the two cases, i.e., magnitude of velocities at each time step at each grid point for the case with the dune subtracted from corresponding values for the case without the dune.

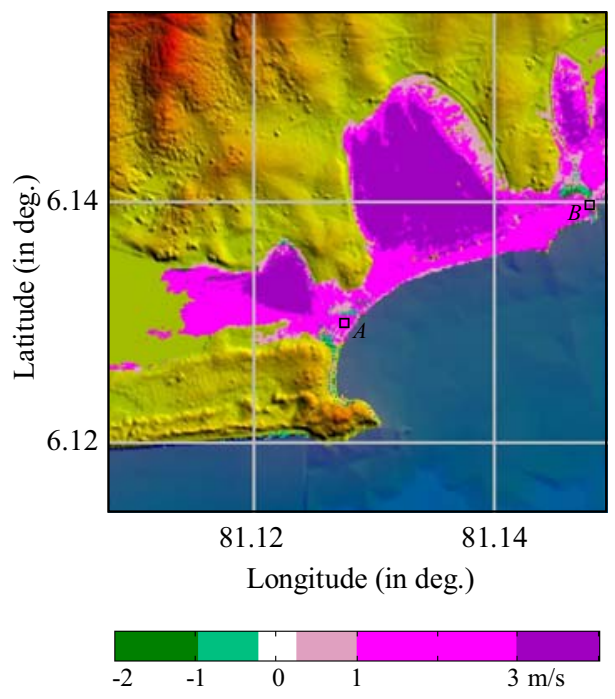

Fig. 16. Computed difference in magnitude of peak flow velocitiess with and without the sand dune. Negative values of the colour scale indicate higher velocities in the case with the sand dune. Elevation scale for topography and bathymetry as in Fig. 8.
We see in Fig. 16 that the flow velocities are higher in the case without the sand dune in most areas, especially over the salterns owing to lower bottom friction. However, we also see a few patches of higher velocities in the case with the dune compared to the case without the dune near and to the south of locality $A$ and just inland of location $B$. This is because the tsunami surge backed up against the sand dune tends to flow faster through the low elevation gaps in coastal topography.

\subsection{Model Limitations}

Finally, it must be added that there are several limitations involved in modelling tsunami inundation described in the present paper. One is that, the resolution of the modeling is no greater or more accurate than the bathymetric and topographic data used. Although, high resolution topographic data were available for the present study, the resolution of the bathymetric data used is much less.

Another significant limitation is that, since the initial condition for the modelling is determined by the displacement of the ocean bottom along the fault line, the largest source of errors is the earthquake model. Nevertheless, the satisfactory verification of the present model against the available field records of the extent of inundation due to the tsunami in December 2004 provided an indication of the reliability of the fault plane model used in the present study. Moreover, the influence of the accuracy of the fault model is probably less important in the present case as we compare only the effect of the sand dune on the tsunami inundation whilst keeping the source parameters the same.

The model results discussed in the present paper examined only the effect of the nearly $2 \mathrm{~km}$ long largescale sand dune lying in the upper part of the bay during the onshore propagation of the leading wave; neither the effect of the stretch of sand dune along the southern part of the coastline of the city nor other smaller-scale dunes scattered along the coastline were considered.

Whilst the results from the present study with the sand dune in place are useful for emergency managers to identify areas that should be evacuated in the event of a major tsunamigenic earthquake in the Andaman-Sunda subduction zone, these results are, however, not intended for land-use regulation owing to the uncertainties inherent in this type of modelling.

\section{Conclusions}

Numerical simulations of the inundation that would be caused by an event similar to the tsunami in December 2004 have been carried out for the city of Hambantota on the south coast of Sri Lanka in order to investigate the effect of a nearly $2 \mathrm{~km}$ long large-scale dune fronting a part of the city. The model results of the spatial distribution of the inundation as well as flow velocities for the case of with the sand dune have been compared with those without the dune. The results appear to indicate that the peak flood flow rates and flow depths are higher in most areas of the city without the dune compared to those with the dune. Some of the inundated areas with higher flow depths and velocities 
in the case of without the sand dune include areas of low population density including the salterns.

However, it appears that the tsunami surge backing up against the high elevated beach fronts including the sand dune causes a rise in nearshore water levels of up to $0.5 \mathrm{~m}$ in the case with the sand dune compared to that without the dune. The magnitude of the flow velocities too appear to be higher in most areas in the case without the sand dune although there are patches of lower velocities at certain low elevation localities with high elevated ground on either side.

\section{ACKNOWLEDGEMENTS}

A part of the work reported in the present paper was supported by NSF Gant No. RG/2005/DMM/02 and USAID/US Indian Ocean Tsunami Warning System (IOTWS) Project Grant No.04-05-IOTWS-06. The author also wishes to thank Prof. Philip Liu and Dr Xioming Wang of Cornell University for kindly making the latest version of COMCOT code available to him to carry out the model simulations described in the present paper and for advice on the use of the same and to the Disaster Management Centre of the Ministry of Disaster Management \& Human Rights of the Government of Sri Lanka for providing him with LIDAR topographic data.

\section{REFERENCES}

Cho, Y.S. (1995). Numerical Simulations of Tsunami Propagation and Run-Up. PhD thesis, Cornell University.

Cox, D., T. Tomita, P. Lynett and R. Holman (2008). Tsunami inundation with macro-roughness in the constructed environment. Proc Int. Conf. on Coastal Engrg., Hamburg.

Department of Census and Statistics, Sri Lanka (2005). Atlas on the Buildings Affected by the Tsunami 2004. ISBN 955-577-514-1; and Tsunami Census 2004/2005 - Final Report. ISBN 955-577-522-2.

ETOPO2 - Two minute Worldwide Bathymetry/ Topography. National Geophysical Data Center (NGDC), USA. Available at: http://www. gfdl.noaa.gov/products/vis/data/datasets/etopo2top ography.html

Fernando, H.J.S., S.P. Samarawickrama, S. Balasubramanian, S.S.L. Hettiarachchi and S. Voropayev (2008). Effects of porous barriers such as coral reefs on coastal wave propagation. Journal of Hydro-environment Research 1, 187194.

Fujima, K. (2001). Long wave propagation on large roughness. In Proceedings of the International Tsunami Symposium (ITS 2001), Seattle, WA, 891895.

Grilli, S.T., M. Ioualalen, J. Asavanant, F. Shi, J. T. Kirby and P. Watts (2007). Source constraints and model simulation of the December 26, 2004 Indian
Ocean tsunami. J. Waterway, Port, Coastal \& Ocean Eng. 133(6), 414-428.

Horrillo, J., Z. Kowalik and Y. Shigihara (2006). Wave dispersion study in the Indian Ocean tsunami of December 26, 2004. Science of Tsunami Hazards 25(1), 42-63.

Ioualalen, M., J. Asavanant, N. Kaewbanjak, S.T. Grilli, J.T. Kirby and P. Watts (2007). Modeling the 26 December 2004 Indian Ocean tsunami: Case study of impact in Thailand. Journal of Geophysical Research 112(C7).

Lay, T. et al. (2005). The great Sumatra-Andaman earthquake of 26 December 2004. Science 308, 1127-1132.

Liu, P.L.F., Y.S. Cho, S.B. Yoon and S.N. Seo (1994) Numerical simulations of the 1960 Chilean tsunami propagation and inundation at Hilo, Hawaii. Recent Development in Tsunami Research, Edited by M. I. El-Sabh, Kluwer Academic Publishers.

Liu, P.L.F., Y.S. Cho, M.J. Briggs, C.E. Synolakis and U. Kanoglu (1995). Run-up of Solitary Waves on a Circular Island. J. Fluid Mechanics 302, 259285.

Liu, P.L.F., S.B. Woo and Y.S. Cho (1998). Computer programs for tsunami propagation and inundation. School of Civil and Environmental Engineering, Cornell University, USA. Available at: http://ceeserver.cee.cornell.edu/pllgroup/doc/cocmot-technical-manual.pdf

Okada, S. (1985). Surface displacement due to shear and tensile faults in a half-space. Bull. Seismol. Soc. Am. 75, 1135-1154.

Papadopoulos, G. A. et al. (2006). The large tsunami of 26 December 2004: Field observations and eyewitness accounts from Sri Lanka, Maldives Island and Thailand. Earth Planets Space 58, 233241.

Silva, R., I.J. Losada and M.A. Losada (2000). Refection and transmission of tsunami waves by coastal structures. Applied Ocean Research 22, 215-223.

Stein, S. and E.A. Okal (2005). Speed and size of the Sumatra earthquake. Nature 434, 581-582.

Tanaka, N., Y. Sasaki, M.I.M. Mowjood, K.B.S.N. Jinadasa and S. Homchuen (2006). Coastal vegetation structures and their functions in tsunami protection: experience of the recent Indian Ocean tsunami, Env Dev Sustain 4, 167-183.

Tomita, T. and K. Honda (2007). Tsunami estimation including effect of coastal structures and buildings by 3D model. Proc. Conference on Coastal Structures, Venice. 
Walsh, T.J., V.V. Titov, A.J. Venturato, H.O. Mofjeld and F.I. Gonzalez (2003). Tsunami hazard map of the Elliott Bay Area, Seattle, Washington Division of Geology and Earth Resources Report No. 200314.

Wang, X. and P.L.F. Liu (2006). An analysis of 2004 Sumatra earthquake fault plane mechanisms and Indian Ocean tsunami. Journal of Hydraulic Research 44(2), 147-154.

Wang, X. and P.L.F. Liu (2007). Numerical simulations of the 2004 Indian Ocean tsunamis: coastal effects, Journal of Earthquake \& Tsunami 1(3), 273-297.

Wijetunge J.J. (2006). Tsunami on 26 December 2004: Spatial distribution of tsunami height and the extent of inundation in Sri Lanka. Science of Tsunami Hazards 24(3), 225-239.

Wijetunge J.J. (2009). Field measurements and numerical simulations of the 2004 tsunami impact on the east coast of Sri Lanka. Pure Appl. Geophys. 166(4), 593-622. 